Thorax, 1980, 35, 593-599

\title{
Cryptogenic fibrosing alveolitis: response to corticosteroid treatment and its effect on survival
}

\author{
M TURNER-WARWICK, B BURROWS, AND A JOHNSON
}

From the Cardiothoracic Institute, Brompton Hospital, London

ABSTRACT We have studied retrospectively 220 patients with cryptogenic fibrosing alveolitis (CFA) who were first seen between 1955-73 and had been followed up for at least four years until 1977. Seventy-seven patients had received no treatment and 143 had received corticosteroids. The only clinical difference between the groups was the age at presentation (untreated mean age 61 years \pm 11 $\mathrm{SD}$; treated mean age 56 years \pm 11 SD $\mathrm{p}<0.001)$. The influence of corticosteroid treatment has been assessed both in terms of the clinical, radiographic, and physiological response after four to eight weeks and in terms of survival, using a log rank method of analysis. Of 143 treated cases 127 had detailed follow-up information. Seventy-two $(57 \%)$ had substantial subjective improvement of breathlessness but only $22(17 \%)$ of the total showed additional objective improvement. The only factors significantly distinguishing the 72 subjective responders from the 55 non-responders, and which therefore might be used as predictors of response, were a younger age at presentation $(\mathrm{p}<0.001)$ and less dyspnoea $(\mathrm{p}<0.02)$. Analysis of survival data demonstrated that treated patients who showed an early good response to steroids had a markedly better survival than non-responders $(p<0.001)$. The survival curve for the untreated group lay between the two steroid groups. Analysis of the survival data suggests that steroid responsiveness relates particularly to a subgroup with an inherently better prognosis, which is characterised by a younger age and probably by a cellular histology not however necessarily typical of desquamative interstitial pneumonia. Nevertheless treatment appears to have an additional influence on survival especially in early disease, which is not observed in the untreated cases. A large number of factors are not related either to steroid responsiveness or to survival and these include the presence of associated "connective tissue" diseases, autoantibodies, and the duration of dyspnoea at presentation. It is concluded that biopsy information is valuable in assessment of potential to respond to steroids and that if steroid treatment is to be helpful it must be used at an early stage. The response is very variable and titration of the steroid dose against an individual patient's response is likely to give better results than adherence to arbitrary dose schedules.

Within the group of patients fulfilling the criteria for idiopathic interstitial pneumonia, it is well recognised that those having histological features of desquamative interstitial pneumonia (DIP) respond well to corticosteroids. ${ }^{12}$ Assessment of steroid response may be based on clinical criteria after a stated interval of treatment, or it may be considered in terms of survival. Some patients may have an improved survival because of arrest or stabilisation of active disease without the demonstration of objective or subjective improvement. Because of the heterogeneity of the condition identification of this group requires study of a large number of patients

Address for reprint requests: Professor M Turner-Warwick, Cardiothoracic Institute, Brompton Hospital, Fulham Road, London SW3 6HP. for many years.

In spite of the difficulties of standardised diagnostic criteria for CFA, the variable histological features of activity at the time of presentation and the varied criteria used for assessing steroid responsiveness, the published results in a number of uncontrolled studies show considerable similarities. ${ }^{2-5}$ The factors relating to steroid responsiveness have not been studied in depth but it has been suggested that women and younger individuals respond better. ${ }^{6}$ Several reports indicate that those with a greater inflammatory cell infiltrate (including a cellular infiltrate in the alveolar walls with or without an accumulation of large mononuclear cells in the alveolar spaces) also respond better. ${ }^{35} 7$

In the present report we attempt to distinguish 
factors influencing an early response to treatment (in terms of subjective or objective improvement) and the influence of steroid treatment on survival.

\section{Methods}

The definition of CFA has been given in a previous paper. ${ }^{8}$ Two hundred and twenty cases fulfilling criteria for CFA who attended any one of 13 physicians at the Brompton Hospital between 1955 and 1973 were reviewed retrospectively and a minimum of a four-year follow-up completed to 31 January 1977. All deaths were verified in the Births and Deaths Register. Adequate follow-up information was obtained in 209 cases. Fifty-three are known to be alive and 156 have been followed to death. Eleven patients are believed to be alive but no details are available; no information regarding the cause of death is available in four of the 156 cases.

The clinical features of this population and the overall life table analyses of survival have already been reported. ${ }^{8}$

Over the 22 years spanned by this study physicians varied in their treatment of CFA. Because of these varied individual policies steroids were not used for a number of different reasons in 77 of the $220(35 \%)$ and were given to $143(65 \%)$. In 32 instances corticosteroids were started before attendance at Brompton and in some analyses these cases will be compared with those who started treatment after attendance at Brompton because there is evidence that the former group may have been referred because they had failed to respond to steroids. Thus, $111(78 \%)$ of the steroid-treated cases started treatment at our hospital. However, in every case treatment was started after 1955-that is, at the beginning of the survey. The mean age at onset of symptoms was 54.9 years \pm 12 SD and the mean age at the start of steroids was 56.0 years $\pm 11.0 \mathrm{SD}$.

The initial doses of corticosteroids given varied and are set out in table 1. Although the exact dose and duration of treatment varied considerably treatment continued indefinitely, usually at a reduced level.

Table 1 Doses of oral corticosteroids in treated patients with cryptogenic fibrosing alveolitis*

\begin{tabular}{lll}
\hline \multirow{2}{*}{$\begin{array}{l}\text { Dose of prednisone or } \\
\text { prednisolone in mg/day }\end{array}$} & \multicolumn{2}{l}{ Treated patients } \\
\cline { 2 - 3 } & Number & $\%$ \\
\hline $10-15$ & 24 & $16 \cdot 8$ \\
$20-25$ & 30 & $21 \cdot 0$ \\
$30-35$ & 35 & $24 \cdot 5$ \\
$40-45$ & 29 & $20 \cdot 2$ \\
$50-60$ & 14 & $9 \cdot 8$ \\
Dose unknown & 11 & $7 \cdot 7$ \\
Total treated & 143 & $100 \cdot 0$ \\
\hline Mean dose 30.3 mg/day \pm 13.3 SD &
\end{tabular}

*Doses at time of assessment of response
The subjective response to steroids was assessed? by review of the patients' hospital notes regardin change in dyspnoea at four to eight weeks after the start of treatment, when patients were usually stiff receiving their initial high dose. Improvements i other symptoms including general wellbeing have् not been included in the definition of subjective. improvement. Improvement of dyspnoea was graded as "much improved," "slightly improved," "initiat improvement" (but relapsing as the dose was reduced), and "none." In this report cases have bee $\overrightarrow{\bar{P}}$ regarded as steroid-responsive if they had muct improvement or initial improvement and un responsive if they showed slight or no improvementer

Objective change was assessed comparing standarê physiological data before and after four to eighe weeks of treatment including measurement of forced expiratory volume in one second $\left(F E V_{1}\right)$, forced vitat capacity (FVC), total lung capacity (TLC), an $\mathrm{FEV}_{1} / \mathrm{FVC}$ ratio. The method of measuring transfep factor for carbon monoxide changed during the course of the follow-up period and has not beeng included in this paper. All the physiological results are presented here as a percentage of the predicte $\Phi$ value. Radiographic change was assessed by paires film analysis, the reader being unaware of the chronological order of the films. All films were also read blind by one reader using the ILO/UQ classification system. ${ }^{9}$

Gradings for the clinical, physiological, radio $\Xi$ graphic, and histological features have bee? described previously. ${ }^{8}$

Survival analysis has been undertaken using a log rank survival routine devised by Peto et al, ${ }^{10}$ in which allowance for age, sex, and other factors cap̃ be made when considering the influence of othe? variables on survival.

\section{Results}

Of 220 patients, 143 were treated with corticos steroids. Table 2 shows the characteristics of the twogroups. The only feature showing a significan difference was the age at onset of dyspnoea and ait presentation (fig 1).

\section{STEROID RESPONSE}

Sufficient information was available in 127 of the 143 cases, but in three of these 127 detailed follow-up information was not available. After four to six weeks treatment, no improvement was observed in $42(33 \%)$, slight subjective improvement in $13(10 \%)$ initial improvement in $26(21 \%)$, and good subjective्ष improvement in $46(36 \%)$. Thus $55(43 \%)$ were classified as non-responders and $72(57 \%)$ a? responders. 
Table 2 Comparison between the clinical features of the untreated and treated cases

\begin{tabular}{|c|c|c|c|c|c|c|}
\hline \multirow[t]{2}{*}{ Features } & & \multicolumn{2}{|l|}{ Untreated $(n=77)$} & \multicolumn{2}{|l|}{ Teated $(n=143)$} & \multirow[t]{2}{*}{$p$} \\
\hline & & Mean $\pm S D$ or number & $\%$ & Mean $\pm S D$ or number & $\%$ & \\
\hline $\begin{array}{l}\text { Sex-male } \\
\text { Age at presentation } \\
\text { Duration of dyspnoea } \\
\text { Grade of dyspnoea } \\
\text { Right heart failure at present } \\
\text { Smoker } \\
\text { Polyarthritis } \\
\text { Other immunological disease }\end{array}$ & & $\begin{array}{l}55 \\
61 \cdot 0 \mathrm{yr} \pm 11 \\
2 \cdot 0 \pm 2 \cdot 6 \mathrm{yr} \\
1 \cdot 4 \\
7 \\
62 \\
13 \\
8\end{array}$ & $\begin{array}{r}9 \\
80 \\
17 \\
10\end{array}$ & $\begin{array}{l}92 \\
55 \cdot 7 \mathrm{yr} \pm 11 \\
2 \cdot 3 \pm 3 \cdot 2 \mathrm{yr} \\
1 \cdot 7 \\
9 \\
100 \\
33 \\
16\end{array}$ & $\begin{array}{r}6 \\
70 \\
23 \\
11\end{array}$ & $\begin{array}{l}\text { NS } \\
0 \cdot 001 \\
\text { NS } \\
\text { NS } \\
\text { NS } \\
\text { NS } \\
\text { NS } \\
\text { NS }\end{array}$ \\
\hline $\begin{array}{l}\text { Physiology } \\
\text { FEV }_{1} \% \text { predicted } \\
\text { FVC \% predicted } \\
\text { TLC \% predicted } \\
\mathrm{PaO}_{2} \text { mmHg }\end{array}$ & & $\begin{array}{l}67 \cdot 9 \pm 18 \\
66 \cdot 5 \pm 17 \cdot 7 \\
74 \cdot 2 \pm 18 \cdot 0 \\
62 \cdot 8 \pm 16 \cdot 9\end{array}$ & & $\begin{array}{l}60 \cdot 7 \pm 19 \\
62 \cdot 7 \pm 19 \\
74 \cdot 9 \pm 22 \\
61 \cdot 3 \pm 16 \cdot 2\end{array}$ & & $\begin{array}{l}0.07 \\
\text { NS } \\
\text { NS } \\
\text { NS }\end{array}$ \\
\hline $\begin{array}{l}\text { Radiographic } \\
\text { Zones } \\
\text { Profusion scores of } \\
\text { irregular opacities }\end{array}$ & & $\begin{array}{l}4 \cdot 2 \pm 1 \cdot 6 \\
1 \cdot 9 \pm 0 \cdot 7\end{array}$ & & $\begin{array}{l}4 \cdot 1 \pm 1 \cdot 7 \\
1 \cdot 7 \pm 0 \cdot 8\end{array}$ & & NS \\
\hline Biopsy & & $(n=7)$ & & $(\mathrm{n}=35)$ & & \\
\hline $\begin{array}{l}\text { Intra-alveolar mononuclear } \\
\text { Interstitial lymphocytes }\end{array}$ & $\begin{array}{l}\text { None/few } \\
\text { Many } \\
\text { None/few }\end{array}$ & $\begin{array}{l}4 \\
3 \\
4\end{array}$ & $\begin{array}{l}57 \\
43 \\
57\end{array}$ & $\begin{array}{l}17 \\
18 \\
23\end{array}$ & $\begin{array}{r}49 \\
51 \\
66\end{array}$ & $\begin{array}{l}\text { NS } \\
\text { NS } \\
\text { NS }\end{array}$ \\
\hline Fibrosis & $\begin{array}{l}\text { Many } \\
\text { None or little }\end{array}$ & $\begin{array}{l}3 \\
2 \\
3\end{array}$ & $\begin{array}{r}43 \\
29 \\
43\end{array}$ & $\begin{array}{l}23 \\
23 \\
12\end{array}$ & $\begin{array}{l}00 \\
34 \\
66\end{array}$ & NS \\
\hline Overall & $\begin{array}{l}\text { Much } \\
\text { Cellular } \\
\text { Fibrotic } \\
\text { Mixed }\end{array}$ & $\begin{array}{l}3 \\
2 \\
3 \\
2\end{array}$ & $\begin{array}{l}43 \\
29 \\
43 \\
29\end{array}$ & $\begin{array}{r}12 \\
14 \\
14 \\
7\end{array}$ & $\begin{array}{l}34 \\
41 \\
41 \\
18\end{array}$ & $\begin{array}{l}\text { NS } \\
\text { NS } \\
\text { NS }\end{array}$ \\
\hline $\begin{array}{l}\text { ANA } \geqslant 1 / 10 \\
\text { DAT } \geqslant 1 / 32 \\
\text { ESR } \mathrm{mm} / 1 \mathrm{hr}\end{array}$ & & $\begin{array}{l}32 / 70 \\
12 / 70 \\
36 \cdot 0 \pm 26 \cdot 5\end{array}$ & $\begin{array}{l}45 \cdot 7 \\
17\end{array}$ & $\begin{array}{l}56 / 122 \\
20 / 122 \\
32 \cdot 6 \pm 25 \cdot 1\end{array}$ & $\begin{array}{l}45 \cdot 9 \\
16 \cdot 4\end{array}$ & $\begin{array}{l}\text { NS } \\
\text { NS } \\
\text { NS }\end{array}$ \\
\hline
\end{tabular}

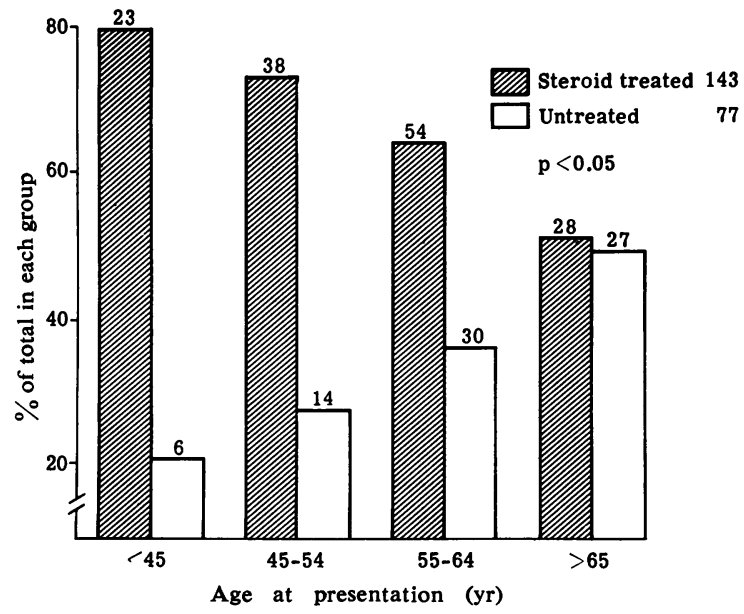

Fig 1 Histogram to show the ages at presentation in treated and untreated groups of patients with cryptogenic fibrosing alveolitis.

Complete clinical, radiographic, and physiological data before and after steroid treatment were available for review in 78 cases. Thirty-five $(45 \%)$ of these showed improvement of dyspnoea and 13 of those with improved dyspnoea also showed improveme.t in the radiograph. Although 29 of the 35 also showed an improvement of at least $10 \%$ in the FVC, only one patient with subjective improvement of dyspnoea showed a greater than $20 \%$ improvement in FVC.

Of the 78 treated patients whose full assessment data were available, only $11(14 \%)$ showed improvement in dyspnoea, as well as improvement in the physiological measurements (FVC greater than $10 \%$ ) and the radiograph.

The clinical features of those responding and not responding to treatment are set out in table 3 . The only significant features associated with a good steroid response were younger individuals $(p<0.001)$ (fig 2) and less severe dyspnoea at presentation $(p<0.02)$. Analyses of the biopsies using a semiquantitative method did not identify steroid responders although there was a trend towards greater numbers of responders having a cellular biopsy with less fibrosis. The presence of immunological disease and the radiographic scores did not differ between the groups. The complications of steroid treatment are listed in table 4 and this shows that about one-quarter of the patients developed important side-effects.

\section{SURVIVAL}

Survival data have been analysed in terms of lifetable survival curves and by analysis of groups of cases dead in less than two years, within two to four 
Table 3 Comparison between the clinical features of steroid responsive and unresponsive cases

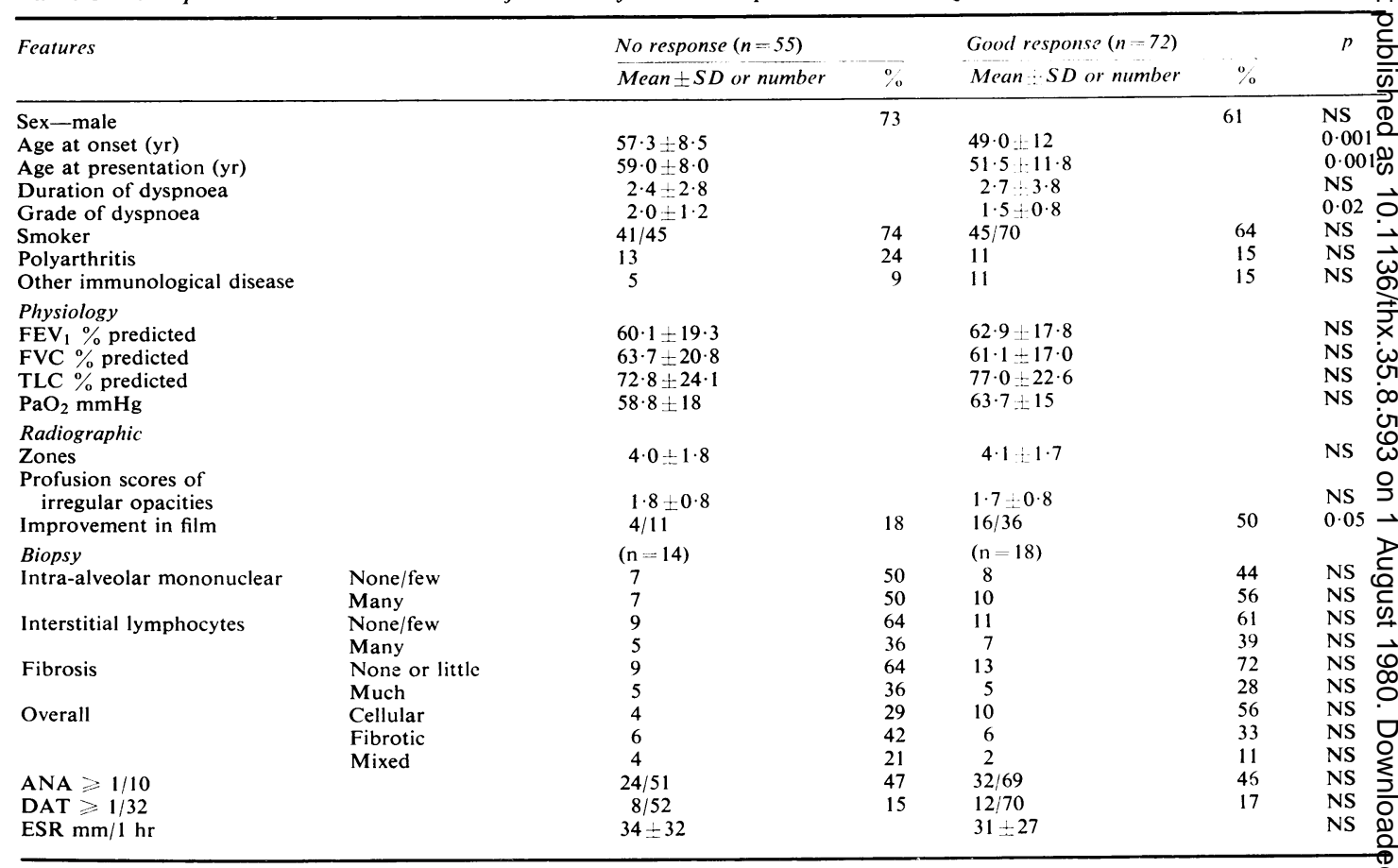

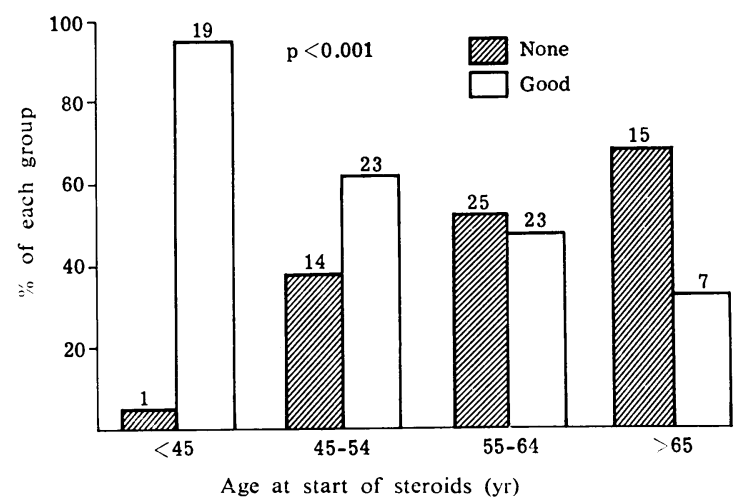

Fig 2 Histogram to show the age distribution of the group of patients responding to corticosteroids (assessment made four to eight weeks after starting treatment) and those showing no response.

years, and alive at four years. The analyses undertaken correlate closely and the results have been pooled (fig 3).

The median survival of untreated patients was 54 months. A longer survival was observed in women $(p<0.03)$, and in those presenting at a younger age $(p<0.02) \quad($ table 5). These factors influenced survival independently in that the differences per-
Table 4 Steroid complications in 127 patients

\begin{tabular}{lccc}
\hline & Number & $\%$ Frequency \\
\hline None & 94 & 74 \\
Fluid overload & 12 & 9 \\
Hypertension & 6 & 5 \\
Peptic ulcer & 6 & 5 \\
Osteoporosis & 5 & 4 \\
Tuberculosis & 3 & 2 \\
Diabetes & 1 & 1
\end{tabular}

There were overall complications in about $26 \%$

Table 5 Analysis of factors influencing survival in untreated and treated cases

\begin{tabular}{|c|c|c|c|c|}
\hline Features & $\begin{array}{l}\text { Untreated cases } \\
(n=77) \\
\text { Factors with } \\
\text { better survival }\end{array}$ & $\begin{array}{l}p \\
<\end{array}$ & $\begin{array}{l}\text { Treated cases } \\
(n=143) \\
\text { Factors with } \\
\text { better survival }\end{array}$ & $\begin{array}{r}p \text { N } \\
<\text { N } \\
\text { N }\end{array}$ \\
\hline Sex & Females & 0.03 & & NS \\
\hline $\begin{array}{l}\text { Age at onset of } \\
\text { symptoms (yr) }\end{array}$ & Younger & 0.06 & Younger & 0.016 \\
\hline Age at presentation (yr) & Younger & 0.02 & Younger & $0.001 \frac{\overbrace{}}{(1)}$ \\
\hline Grade of dyspnoea & & NS & Lesser grade & $0.03 \mathrm{~W}$ \\
\hline Radiographic score & & NS & $\begin{array}{l}\text { Lesser } \\
\quad \text { profusion }\end{array}$ & 0.0020 \\
\hline Histology & & NS & More cellular & $0.01 \overline{\mathrm{O}}$ \\
\hline Early steroid response & & & $\begin{array}{l}\text { Good } \\
\text { response* }\end{array}$ & $0.00 \stackrel{\mathbb{D}}{\overparen{R}}$ \\
\hline
\end{tabular}

*A good steroid response was associated with improved survival after correction (for comparability with non-responders) for all othe factors except histology. 


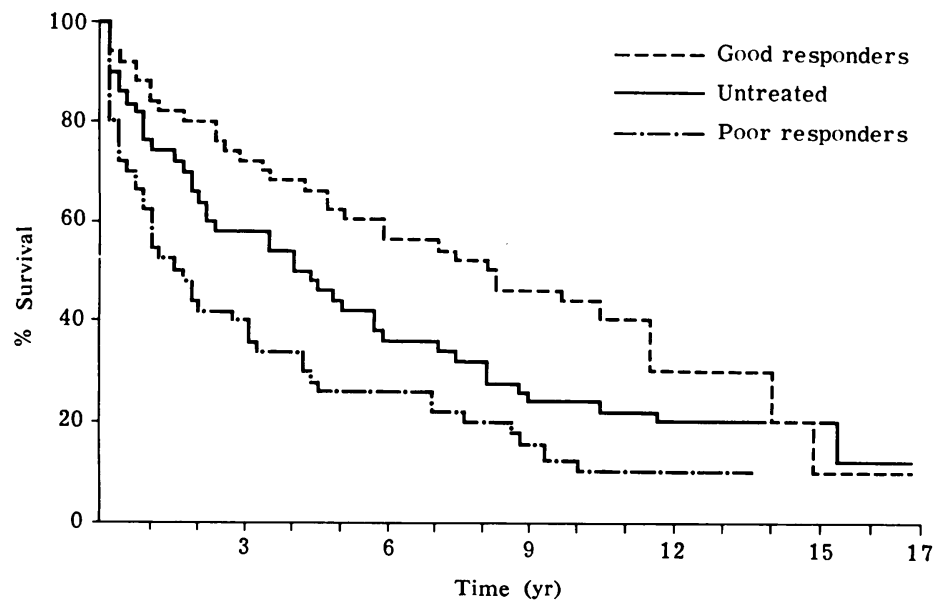

Fig 3 Survival curve for steroid responsive, steroid failures, and untreated patients.

sisted when appropriate adjustments for age and sex had been made. Survival in untreated patients was not related to any other factors analysed.

Among the treated patients a longer survival was noted not only in the younger patients but also in those with less dyspnoea $(p<0.03)$, lesser radiographic profusion $(\mathrm{p}<0.002)$, and greater cellularity of the biopsy $(\mathrm{p}<0.01)$.

There was a strong relationship between longer survival and an early good response to steroids $(p<0.001)$. The improved survival seen in the good steroid responders was still observed after corrections (to be comparable with non-responders) had been made for age, sex, duration and severity of dyspnoea, physiological and radiological severity, the presence of immunological disease, autoantibodies, and the presence of right heart failure. The significant effect on survival is, however, eliminated when corrected for cellularity of the biopsy, suggesting that the effect of steroids is closely linked with more acute histological changes.

In an attempt to obtain evidence of stabilisation of disease by steroids irrespective of early subjective or objective improvement, the survival of steroid treated and untreated groups were compared but no overall difference was observed even after age and sex correction. Of 55 steroid non-responders 10 $(18 \%)$ were still alive at the end of four years and this was significantly worse than the $31(40 \%)$ of 77 untreated cases alive after a similar period $(p<0 \cdot 05)$. However, analyses not detailed here show that the steroid non-responders tend to have more severe disease at presentation than the untreated group, which limits the significance of this comparison.

FOLLOW-UP DATA ON THOSE LIVING COMPARED WITH THOSE DEAD

One hundred and fifty-six patients have been followed to death and 53 are still alive. The mean survival of those followed to death was $3 \cdot 4$ years $\pm 3 \cdot 7$ SD and of those surviving $8 \cdot 8$ years $\pm 3.8 \mathrm{SD}$. Of the living treated patients in whom the response was known, $25(69 \%)$ of 36 showed good improvement compared with the treated patients who died, where only $19(22 \%)$ of 88 showed such a response $(\mathrm{p}<0.001)$.

\section{Discussion}

That corticosteroid treatment is associated with subjective and objective improvement within a few weeks in a group of patients having signs and symptoms of disease over a much longer period of time is good evidence that steroids are directly related to such a response. Although a formal analysis of clinical change at four to eight weeks was not systematically recorded in the untreated patients in this retrospective study, nevertheless follow-up review of the radiographs and physiological measurements in the untreated group not reported in detail in this paper shows that objective improvement rarely occurred. This is in accord with Carrington et $a l^{2}$ who showed that no case of usual interstitial pneumonia improved spontaneously over a six to 12 month period.

The frequency of subjective or objective improvement observed after four to eight weeks treatment is similar to that in previous reports (table 6). The present study has shown that steroid responsiveness assessed after one to two months trial of therapy is reflected in an improved long-term survival as suggested by Stack et l. $^{3}$

While an early prediction of prognosis is of clinical importance, it cannot be concluded that a longer survival is necessarily caused by steroid treatment. An alternative explanation is that steroid 
Table 6 Reported frequency of steroid responsiveness in cryptogenic fibrosing alveolitis or usual interstitial pneumonia

\begin{tabular}{|c|c|c|c|c|c|}
\hline \multirow{3}{*}{ Stack et al ${ }^{3}$} & \multirow{2}{*}{$\begin{array}{l}\text { Number of } \\
\text { cases studied }\end{array}$} & \multicolumn{2}{|c|}{$\begin{array}{l}\text { Subjective } \\
\text { improvement } \\
\text { Number } \% \\
\text { improved }\end{array}$} & \multicolumn{2}{|c|}{$\begin{array}{l}\text { Subjective and } \\
\text { objective improvement } \\
\text { Number \% } \\
\text { improved }\end{array}$} \\
\hline & & 28 & 41 & 11 & 16 \\
\hline & 26 & No & corded & 3 & 12 \\
\hline Murao et al 4 & 131 & 92 & 70 & 31 & 24 \\
\hline Wright et al 5 & 40 & 24 & 60 & 12 & 30 \\
\hline Present series & 78 & 35 & 45 & 13 & 17 \\
\hline Totals & 344 & 179 & 25 & 70 & 20 \\
\hline
\end{tabular}

responsiveness identified a subgroup of patients having an inherently better prognosis. This suggestion is supported by the observation that the survival curve for untreated cases (which as we have demonstrated appears to have characteristics very comparable to the treated group) lies between that for good and that for poor responders (fig 3). Further support for this argument is obtained from the analysis of factors influencing the difference ketween the survival curves for good and nonresponders. Using the log rank method ${ }^{10}$ to make allowance for many factors relating to severity of disease, survival in the responsive group remained better than in the non-responders. However, when allowance was made for cellularity of the biopsy (of mixed inflammatory cells but not necessarily fulfilling criteria for DIP) the difference in survival between the two groups was eliminated. This suggests that the improved survival in the steroid responsive group is closely related to a cellular biopsy; whether this be by association or by cause and effect is not proved. Unfortunately histology was not available in enough untreated cases to demonstrate conclusively whether a cellular biopsy implies as good a prognosis in this group as in the steroid responsive group, although some effect was observed in that all three patients with a "fibrotic" biopsy were dead within two years while both patients with a cellular biopsy were alive after 17 and 13 years. On the other hand, there are three pieces of evidence which suggest that steroids have an influence on survival, beyond identifying a group with a better prognosis. First, if the latter was so, the factors relating to a better survival in the treated and untreated groups should be identical but this is shown not to be the case (table 5). A better survival among treated cases can be identified with a number of factors relating to earlier disease which are not significantly related to a better survival in untreated cases. This suggests that steroids are having some additional influence on survival. Second, on the hypothesis that steroid responsiveness operates only as a marker for a subgroup with an inherently better prognosis, then once identification of this has been obtained at one to two months, it should be possible to stop steroids at this point without relapse and wit good survival. Although this has never been teste formally it is common experience that relapse occure not infrequently as the dose of steroids is reduced Thirdly, the fact that the group with better survivat has been defined in terms of subjective or objective. improvement or both, strongly suggests that steroids have a direct influence on lung pathology. $\vec{\omega}$

In summary, the analyses presented here sugges to us that steroid responsiveness occurs especially i a subgroup of patients who have to some extent ain inherently better prognosis and that this probable includes younger patients with more cellulaxg pathology. Nevertheless our data provides some evidence that steroid therapy has an additiona influence on survival in some patients.

It is also important to establish whether steroids can increase survival without short-term measurable improvement. No evidence was found for this in thee present study when the survival of untreated case was compared with that of the group unresponsive to steroids. Indeed the survival of the untreated patients was better than that of non-responders This observation might suggest that steroids actual accelerate the course of disease in some instance Before attributing such sudden deterioration steroids it must also be noted that we have observed sudden acceleration in progression in individu馬 patients before introduction of steroids and indee this is not infrequently the reason for their referral hospital. On the other hand the fact that the correla tion between cellular histology and survival was stronger than the correlation between cellulf histology and steroid responsiveness suggests that corticosteroids may arrest the inflammatory cont ponent of disease without actual monitored improve्ement in some cases.

Finally a comment should be made about the early deaths among the steroid responsive group. Some of these were from unrelated causes in th middle-aged and elderly population. Others may wet have been caused by a reduction of steroid dosed without adequate and careful monitoring of the clinical response in the individual patient. Othe cases however showed an initial response and $\mathrm{m}$ spite of careful observation and titration of drugg, relapsed. The reason for this transient response unknown but has been observed in our curre prospective survey.

We should like to thank all the Physicians at the Brompton Hospital for allowing us to review their patients. Dr KWF Hinson kindly assessed the lumg biopsies. We also thank Miss Ruth Honey for her painstaking help with documentation. 


\section{References}

1 L. iebow AA, Steer A, Billingsley JG. Desquamative interstitial pneumonia. Am J Med 1965; 39:369-404.

2 Carrington CB, Gaensler EA, Coutu RE, Fitzgerald MX, Gupta RG. Natural history and treated course of usual desquamative interstitial pneumonia. N Engl J Med 1978; 298:801-9.

3 Stack BHR, Choo-Kang YFJ, Heard BE. The prognosis of cryptogenic fibrosing alveolitis. Thorax $1972 ; 27: 535-42$.

4 Murao M. Idiopathic pulmonary fibrosis. Report of the nationwide project research in Japan. XIII World Congress on Diseases of the Chest. Chest 1980; in press.

5 Wright PH, Heard BE, Steel SJ, Turner-Warwick M. Trephine biopsy histology in the management of cryptogenic fibrosing alveolitis. In preparation.

6 Livingstone JL, Lewis JG, Reid L, Jefferson KE.
Diffuse interstitial pulmonary fibrosis. A clinical, radiological and pathological study on 45 patients. Q J Med 1964; 233:71-102.

7 Dreisin RB, Schwartz MI, Theofilopoulos AN, Stanford RE. Circulating immune complexes in the idiopathic interstitial pneumonias. $N$ Engl $\mathrm{J} \mathrm{Med}$ 1978; 298:353-7.

8 Turner-Warwick M, Burrows B, Johnson A. Cryptogenic fibrosing alveolitis: clinical features and their influence on survival. Thorax 1980; 35:171-80.

9 UICC Committee. Cincinnati classification of the radiographic appearances of pneumoconioses: a co-operative study by the UICC Committee. Chest 1970; 58:57-67.

10 Peto R, Pike MC, Armitage $\mathrm{P}$ et al. Design and analysis of randomized clinical trials requiring prolonged observation of each patient. $\mathrm{Br} J$ Cancer 1977; 35:1-39. 